\title{
The New Arched Bridge over Dnipro in Kyiv
}

\author{
Michael Korniiev \\ OOO «Киевстройпроект»/JSC “Kievstroyproject” (website: kstpr.org), Kiev 02140, Ukraine
}

\begin{abstract}
The Podilskyi Arch bridge is crossing the Dnipro River in center of Kiev and is part of a 7.4 km long link which connects the center of Kiev with the "sleeping district" on the left bank of the river. The bridge has a main span of $344 \mathrm{~m}$ intended for six lanes of vehicles in the top level and two metro lines in the bottom level plus large diameter water pipes. The bridge is of steel, except of the reinforced concrete bases of the lower parts of the arches. The draft design works began in 1991 and in 2005 parallel design and construction work started. Due to the financial crisis in Ukraine, the work was interrupted for several years but construction recommenced in 2018 and the bridge is now planned to be completed in 2020 and the first stage of the transition in 2022.
\end{abstract}

Keywords: Ukraine, Podilskyi bridge crossing, Dnipro River, composite steel and concrete road overpasses, arch bridge, loads and reliability factors, steel and concrete structure, orthotropic plate for rail transport, locked coil ropes, planning, design, material, installation.

\section{General}

Ukraine, the largest country in Europe with a population of more than 47 million, is divided from the North to the South by the Dnipro River. Hydroelectric power stations along the river have formed artificial seas. Big cities such as Kyiv, Cherkasy, Dnipro, Kremenchuk, Zaporizhzhya and Kherson are separated by Dnipro.

Kyiv, a city with more than 3 million inhabitants, is experiencing a shortage of bridges over the Dnipro River like other cities. Every day, more than 300,000 vehicles cross the Dnipro River by five Kyiv bridges (Fig. 1). These are not only Kyiv's vehicles, but also transit ones, as the nearest bridge over the Dnipro at a distance of $150 \mathrm{~km}$.

To reduce permanent traffic jams, Kyiv needs several new bridges. The bridge over the Dnipro in the central part of Kyiv should have a large span and be rigid, as in addition to road transport it should carry rail transport. For this purpose, cable-stayed and arched schemes are suitable. However, since there are already 2 big cable-stayed bridges built in Kyiv, the choice fell on the arched variant.

Corresponding author: Michael Korniiev, Dr., chief engineer of the bridge project. E-mail: m.korniev@gmail.com.
The bridge over the Dnipro River is a part of a large bridge crossing (Figs. 2-7), with a total length of $7.4 \mathrm{~km}$. The crossing consists of 5 steel bridges, 2.8 $\mathrm{km}$ of reinforced concrete double-decker combined road and railroad bridges and $1.2 \mathrm{~km}$ of road overpasses [1-3].

The design of the bridge, as well as most of the bridge structures, started in 2005, by 2007 the design of the arch bridge had been developed, and the erection of the bridge had already started. By 2008, most of the metal structures had been installed, but then construction stopped. Almost 10 years of work were frozen, and only from 2017 did they renew. The bridge is now planned to be completed in 2020 and the first stage of the transition in 2022.

\section{Layout and Design of Bridge Structures}

Combined steel-concrete overpasses and large steel bridges have double-deck locations for road and rail transport. There are cars in the top level and rail transport in the bottom. Such a compact layout allowed to reduce the use of land, as well as to make the construction cheaper.

Composite steel and concrete road overpasses with spans up to $40 \mathrm{~m}$ have a steel consumption of 195 $\mathrm{kg} / \mathrm{m}^{2}$, and for rail transport $-200 \mathrm{~kg} / \mathrm{m}^{2}$. 


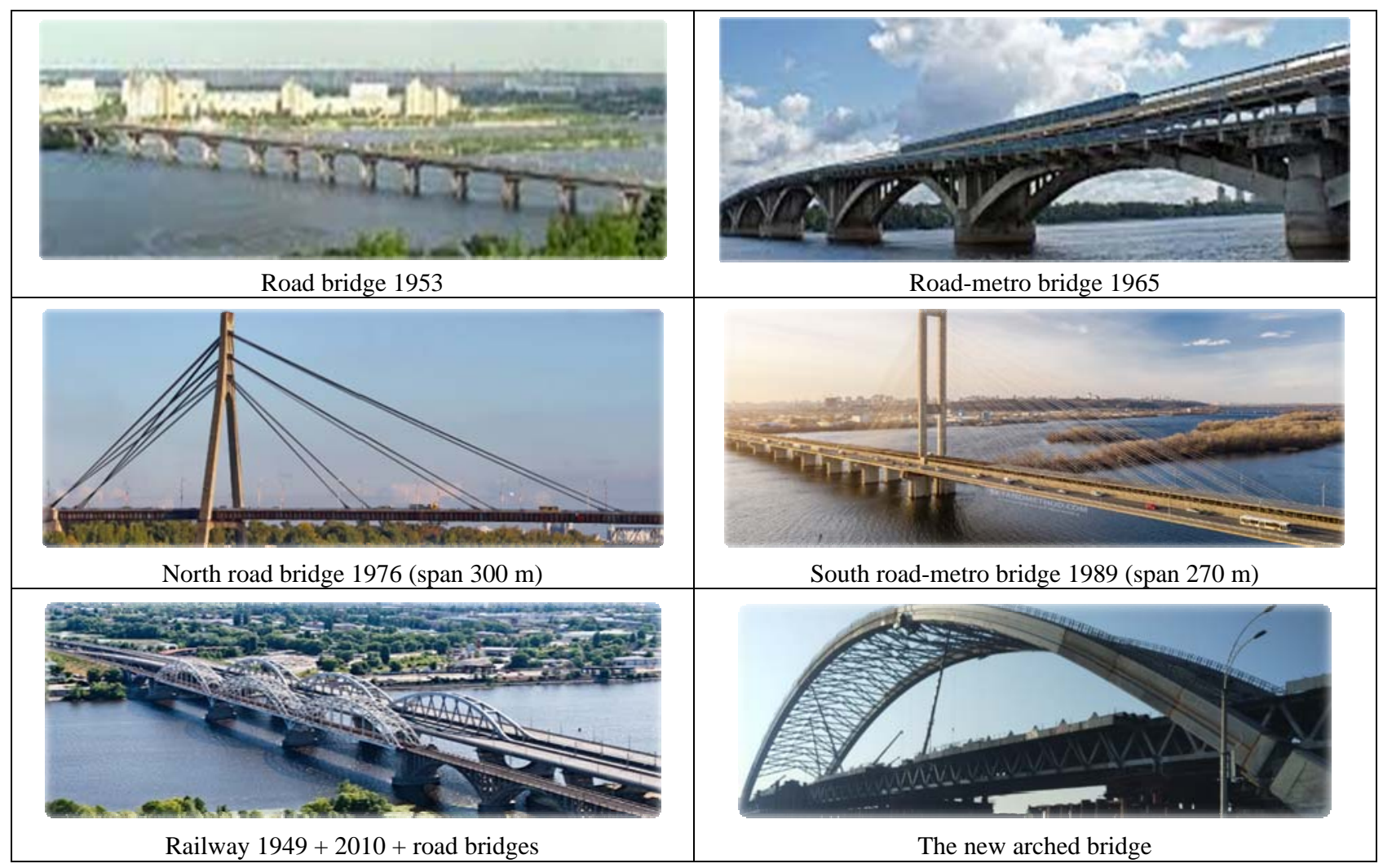

Fig. 1 Kyiv road bridges over the Dnipro.

$7.4 \mathrm{~km}$

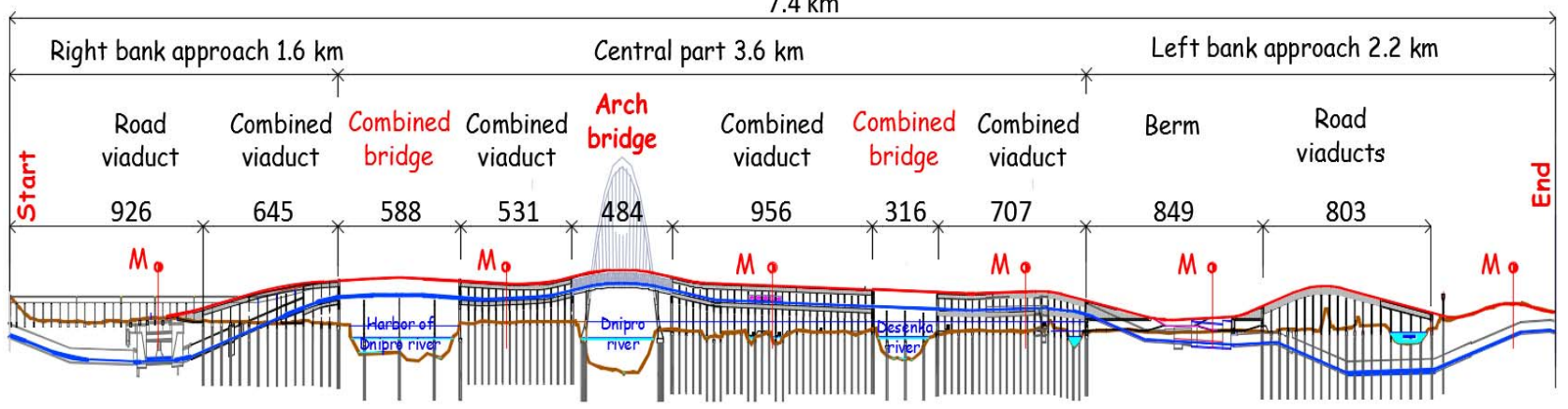

Fig. 2 Scheme of bridge crossings.

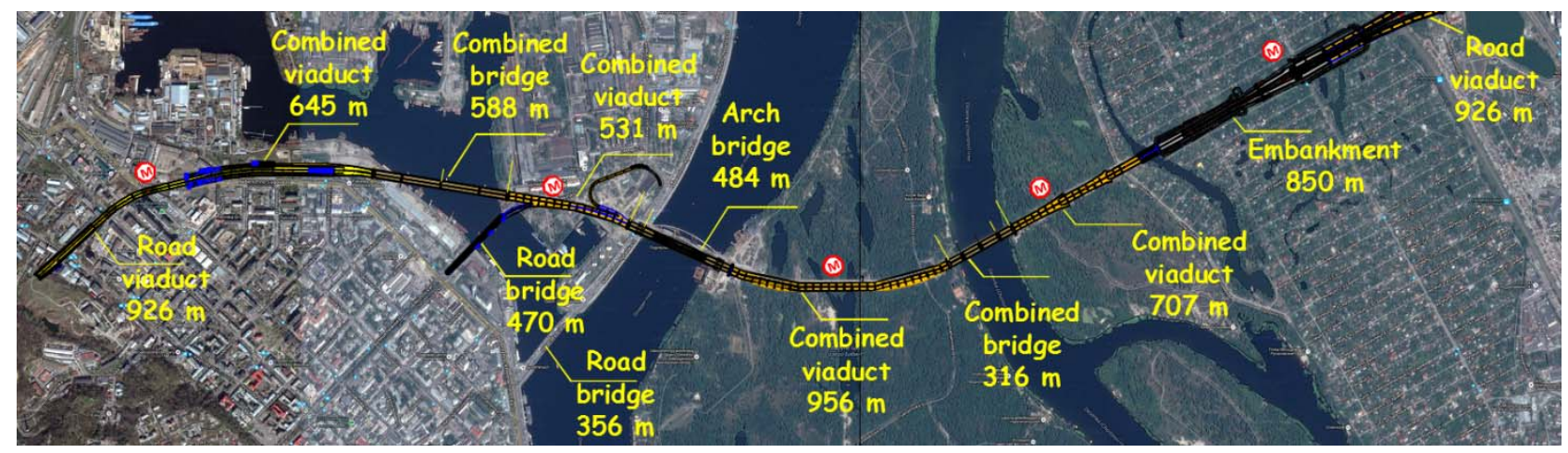

Fig. 3 Location of bridge structures in the plan. 


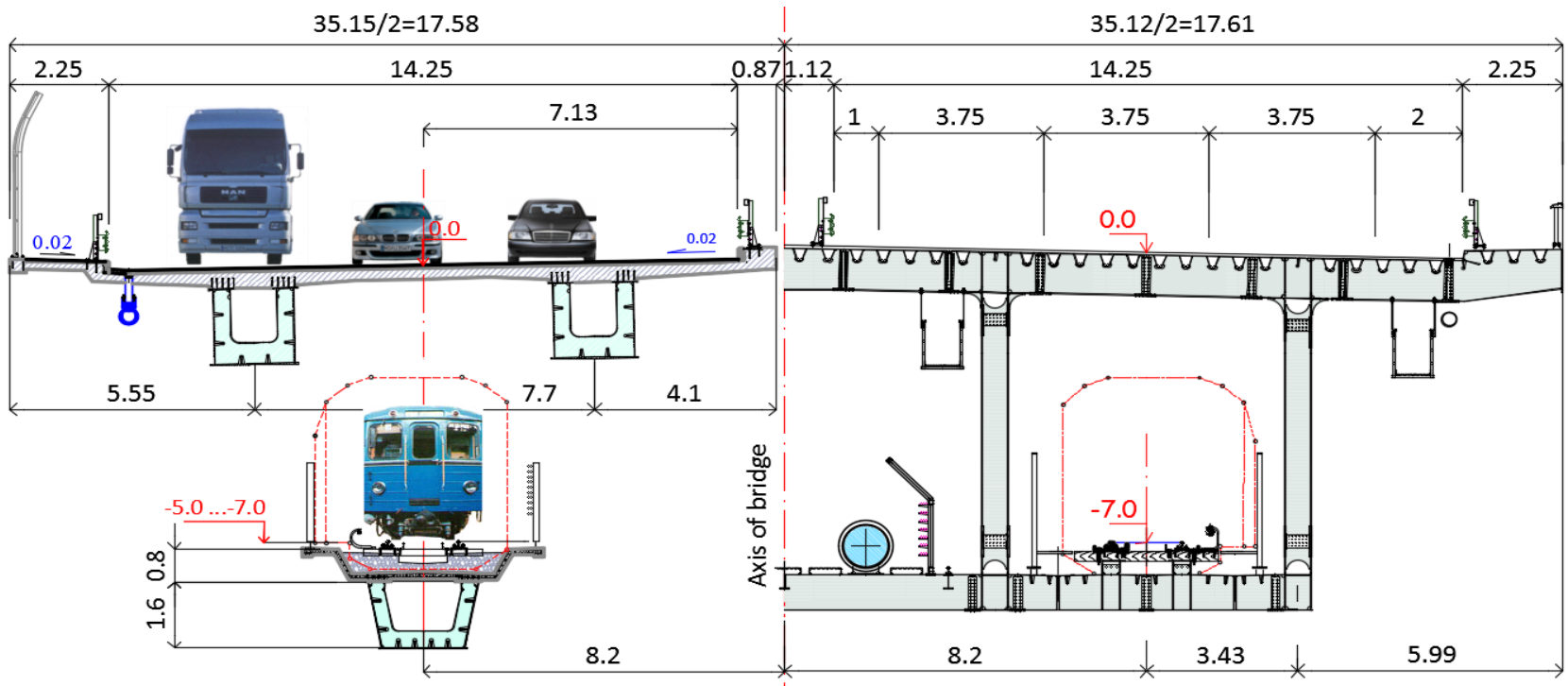

Fig. 4 Combine road-metro two-level bridges and overpasses.

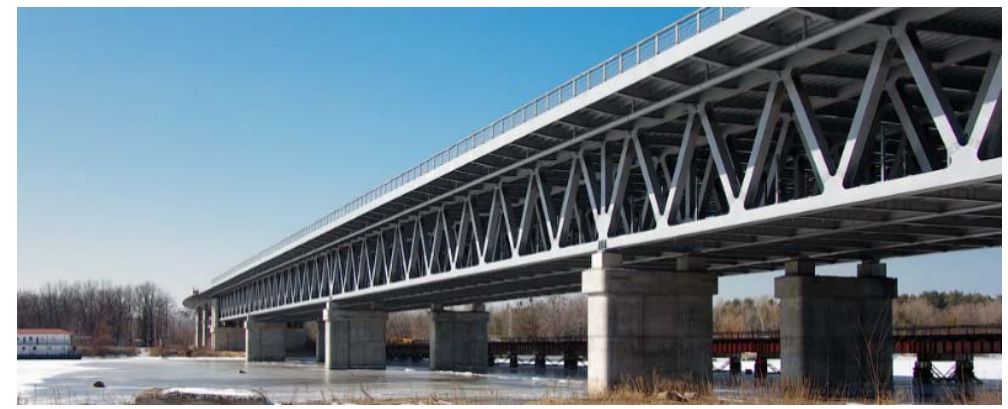

Fig. 5 Combine road-metro two-level bridges over Desenka River, 2009.
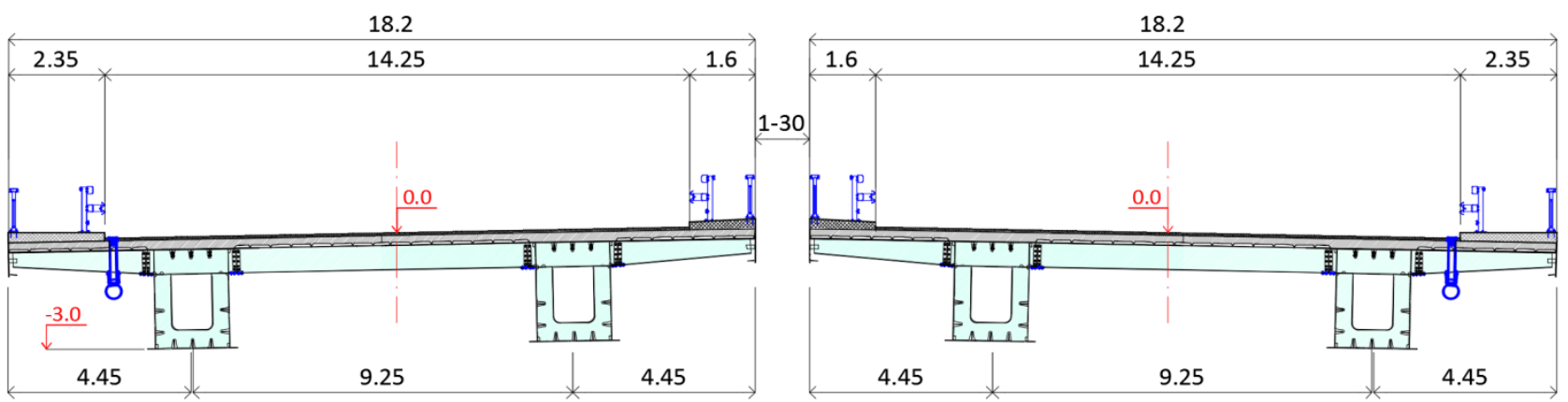

Fig. 6 Cross-section of composite steel-concrete overpasses.

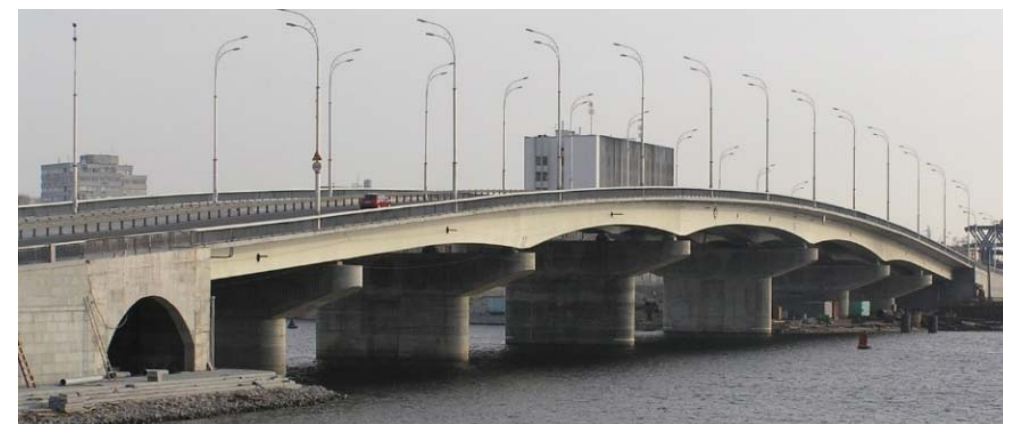

Fig. 7 Road bridges over the Dnipro Harbor. 
The bridge over the Desenka River, completed in 2009, is shown in Fig. 5. Double-deck trusses are used on this bridge.

Highway overpasses with spans up to $70 \mathrm{~m}$ are made of composite steel and concrete, with deck and cross beam support, specific steel consumption of 220 $\mathrm{kg} / \mathrm{m}^{2}$.

There are two road bridges across the Dnipro Harbor. Now a steel bridge is being built, and a steel-concrete bridge was built in 2008 .

\section{Arched Bridge over the Dnipro River}

The bridge over the main riverbed of the Dnieper differs in complexity and size from other structures.

The arch bridge has a main span of $344 \mathrm{~m}$. The bridge is designed for 6 lanes of road and two tracks of rail transport. Large-diameter pipes with water are laid on the bridge. The bridge span is made of steel, except for the base parts of the arches, which are made of reinforced concrete (Fig. 8). The shape of the arch is close to the circular curve; the ratio of arrow to span is 0.192 .

The main loads on the bridge, characteristic and design, are shown in Table 1 . It can be seen, that the useful part of the loads is equal to $28 \%$ of total loads. The bridge was designed according to the bridge standards in 2006. In new bridge standards 2010, reliability coefficients have been increased both to constant and transport loads.

Double-decker truss with $35.8 \mathrm{~m}$ wide bridge top deck suspended at the edges of the ropes from the arches (Fig. 9). Between the arches, there are tubular links. The total weight of steel structures of the arch span structure is 16 thousand tons.

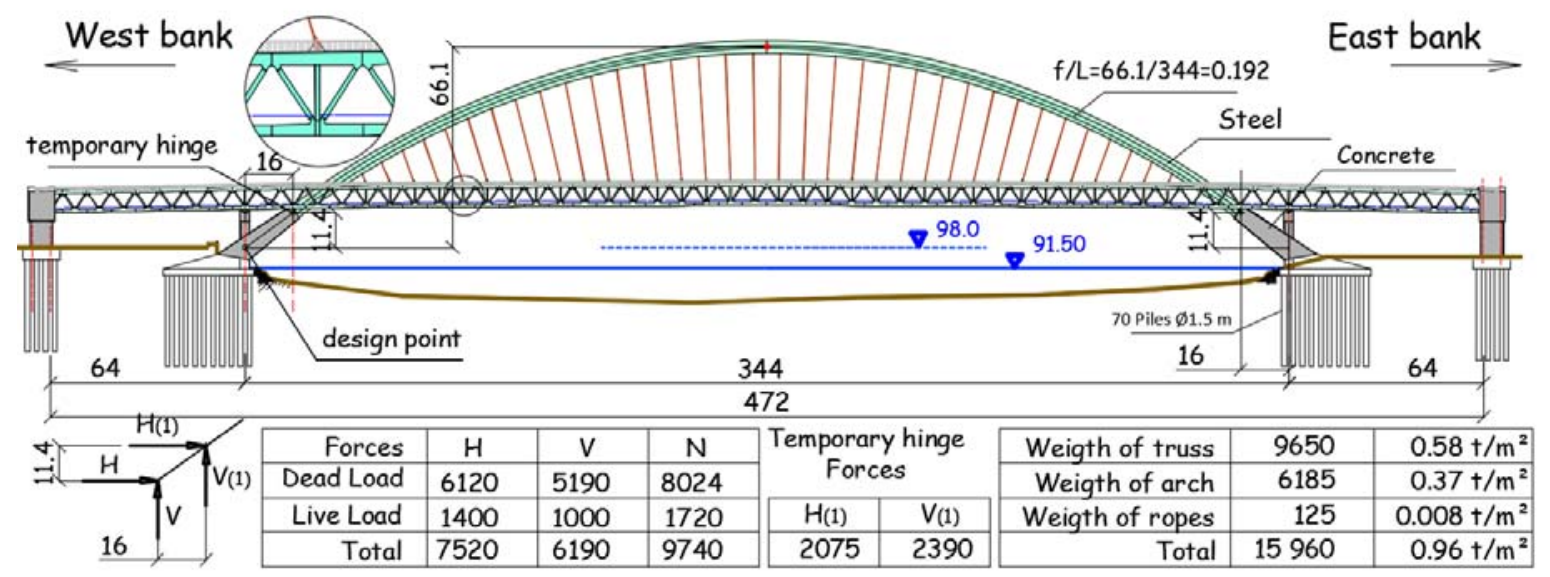

Fig. 8 Arch Bridge. Main parameters.

Table 1 Loads and reliability factors.

\begin{tabular}{|c|c|c|c|c|c|c|c|}
\hline \multirow{2}{*}{ Name of loads } & \multicolumn{2}{|c|}{ Factors } & \multicolumn{2}{|c|}{ Loads, t/m } & \multirow{2}{*}{\multicolumn{2}{|c|}{ - Load share }} & \\
\hline & $\gamma_{f}$ & $M M$ & Character & Design & & & \\
\hline Arch self-weight & 1.1 & - & 20.0 & 22 & $25 \%$ & \multirow{5}{*}{ 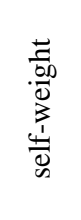 } & \multirow{4}{*}{ 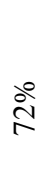 } \\
\hline Truss self-weight & 1.1 & - & 19.1 & 21 & $24 \%$ & & \\
\hline Wearing surface & 2.0 & - & 6.0 & 12 & $14 \%$ & & \\
\hline Rail track weight & 1.5 & - & 1.6 & 2.4 & $3 \%$ & & \\
\hline Auxiliary constructions & 1.3 & - & 4.7 & 6.1 & $7 \%$ & & \multirow{4}{*}{ 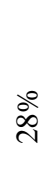 } \\
\hline Water pipes & 1.3 & - & 4.05 & 11.1 & $6 \%$ & \multirow{3}{*}{ 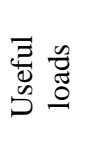 } & \\
\hline Car load & $\sim 1.2$ & $\sim 1.9$ & 7.1 & 11.1 & $12 \%$ & & \\
\hline Subway load & $=1,2$ & $=1.2$ & 6.25 & 8.7 & $10 \%$ & & \\
\hline Total & & & 69.0 & 88.8 & $100 \%$ & & \\
\hline
\end{tabular}




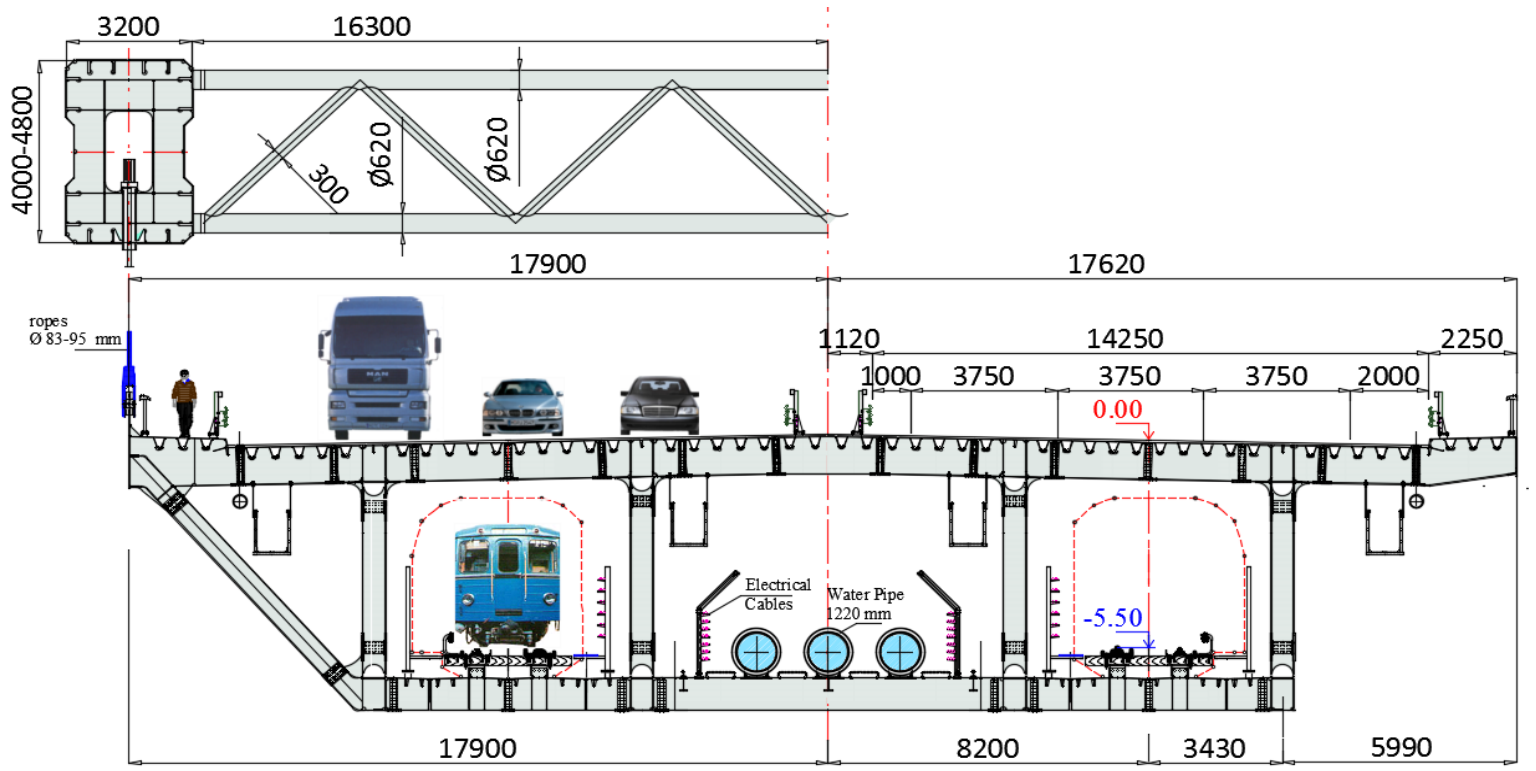

Fig. 9 Cross section of arched bridge.

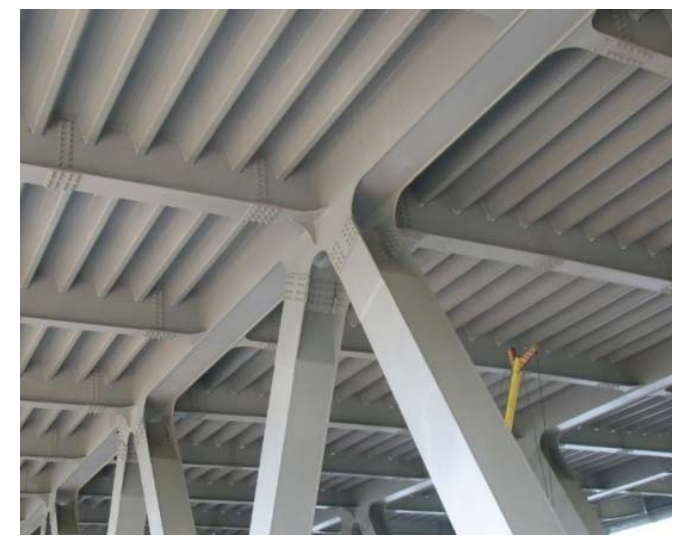

Fig. 10 View of top orthotropic plate.

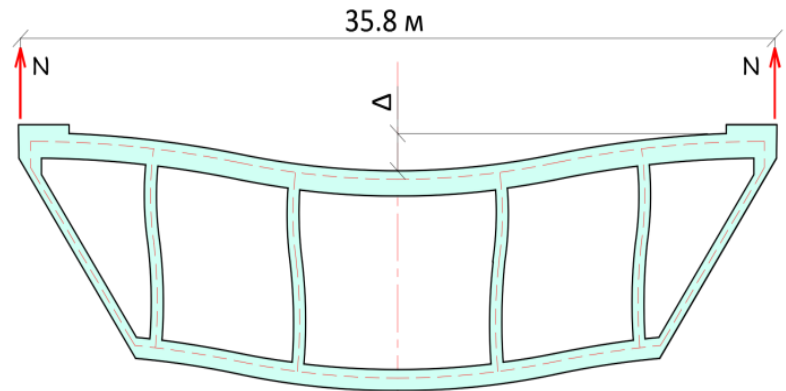

Fig. 11 Typical transverse deformation of the truss.

The top deck of the bridge for road transport is made of orthotropic plate of standard design. Closed longitudinal ribs are supported by crossbars with a step of $4.0 \mathrm{~m}$. Closed truss belts are part of the deck (Fig. 10). The plate thickness is $14 \mathrm{~mm}$ and the thickness of the longitudinal ribs is $8 \mathrm{~mm}$ constant for the whole bridge plate. The characteristic difference between this plate and the standard one is the more powerful cross beams. The wall thickness of the cross beams in the suspension area is $20 \mathrm{~mm}$, and in normal areas 14 $\mathrm{mm}$ with a beam height of $1.0 \mathrm{~m}$. This is due to the fact that the suspension of the truss between the ropes leads to its bending in the transverse direction of the truss, which leads to frame moments and high shear forces, as in the case of Wirendel's truss (Fig. 11).

The anchorage of the suspension ropes on the beam is in steps of $8 \mathrm{~m}$. The anchorage unit is adapted to the fork anchor and represents an eyelet made as an extension of the sidewalk sheet. At the joints of the rope, the plate console is held by an inclined cross member of the truss.

Orthotropic plate for rail transport has an original design [4].

Closed longitudinal rectangular ribs are located above the flooring plate, and cross beams and secondary longitudinal ribs from below (Figs. 12 and 13). Calculations have shown that the fatigue resistance of such a structure allows it to be used for 100 years of operation (Fig. 14). Thirty (30) years of experience in the operation of the plate of a similar design on the cable-stayed Southern bridge in Kyiv (see Fig. 1), showed its durability. 


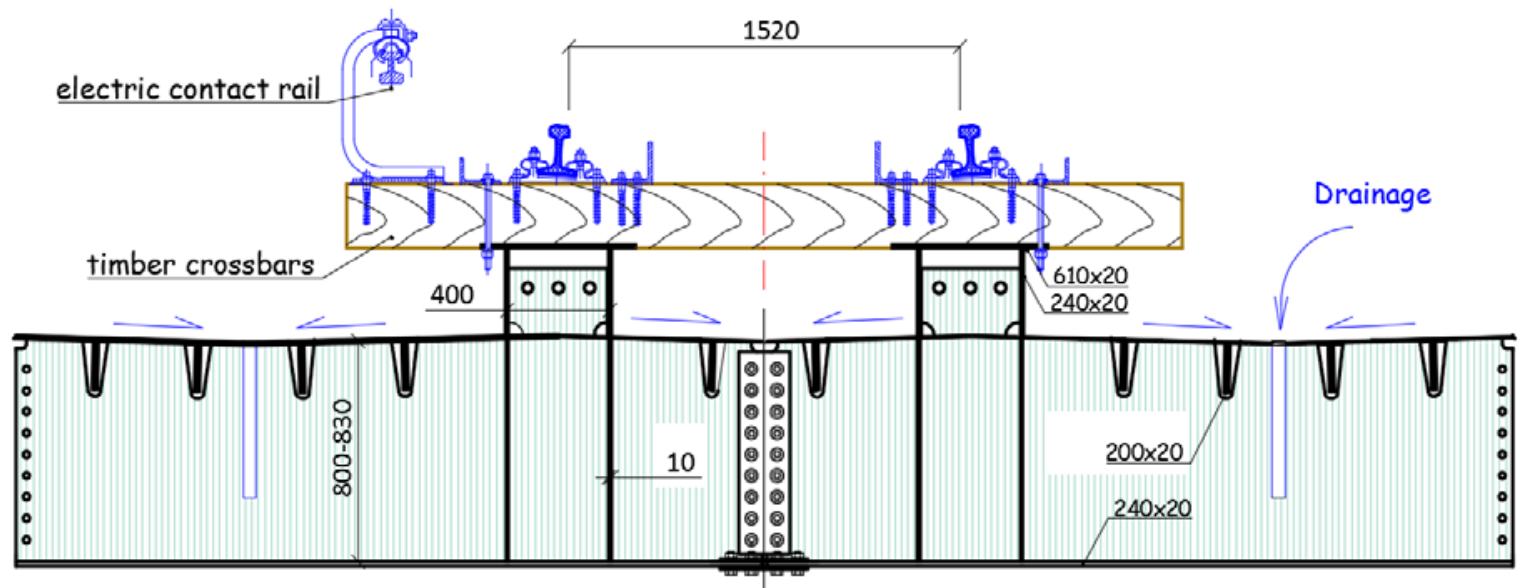

Fig. 12 Cross section of orthotropic plate for rail transport.

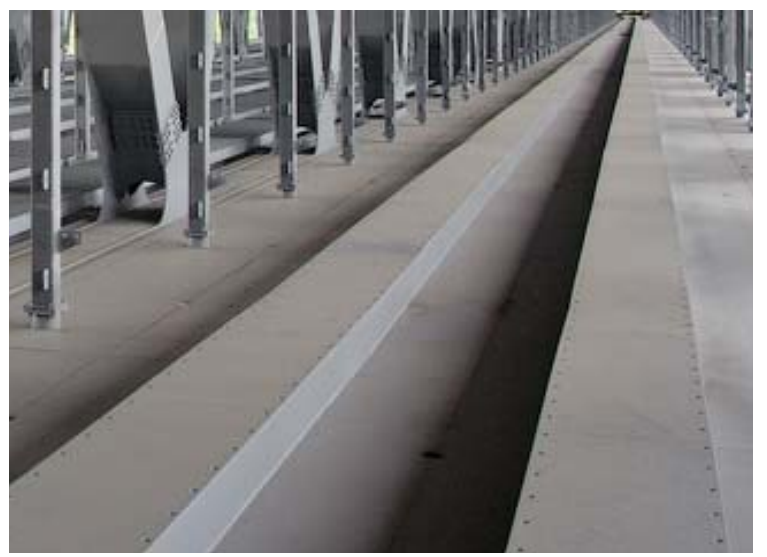

Fig. 13 View of the railroad plate.

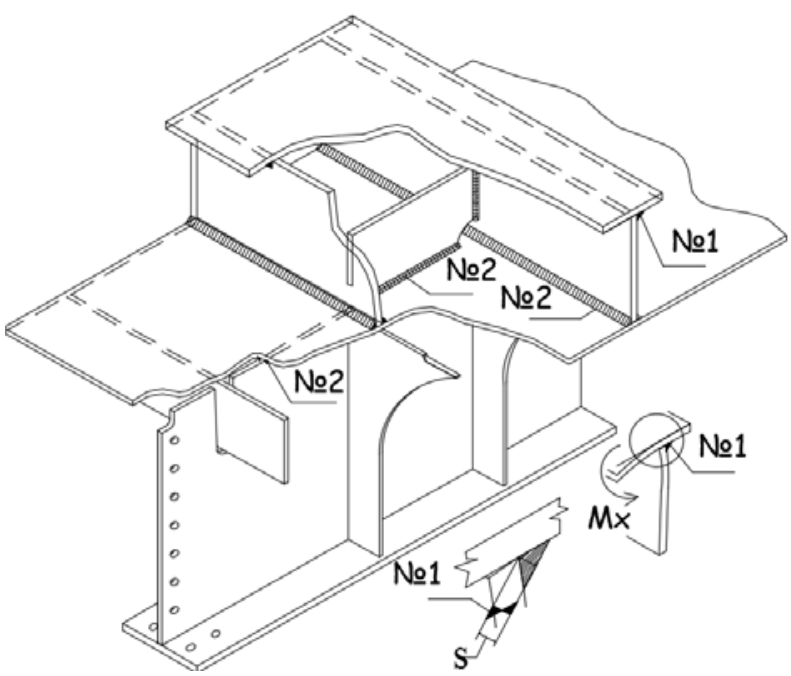

Fig. 14 Scheme for fatigue assessment.

Diagonal elements of trusses (Fig. 15), in addition to the axial forces subject to bending both in the plane of the truss and out of the plane. The cross-section of diagonal elements is box-shaped, and the joints are
I-beam. The I-gauge section simplifies the construction of the joints between the diagonal elements and the truss belts. The joints are made on high-strength bolts.

Cross-section arches are boxes with a constant width of $3.2 \mathrm{~m}$ and a height of $4.8 \mathrm{~m}$ at the bottom and $4 \mathrm{~m}$ in the middle of the arch (Fig. 16). To improve the appearance of the box, the corners of the box are cut and the central part of the wall is pressed in. For the arch the steel of strength class C390 with thickness up to $50 \mathrm{~mm}$ was used. The cross section of the arch is formed of two halves. The joints of the contour sheets are welded.

In the places where the ropes are attached to the arch, there is a thick-walled pipe, which is welded to the diaphragm. The forces from the rope are transferred to the end of the pipe, and then through the diaphragm to the walls of the arch.

The joints of the contour sheets of the arc mounting blocks are made by welding (Fig. 17). The thicknesses to be welded are up to $50 \mathrm{~mm}$. The joints of the longitudinal ribs inside the arch are made on friction joints with high-strength bolts.

The joints on the high-strength bolts were used for all joints, where it was possible, due to the possibility to accelerate the installation and use less qualified labor force. But, welding of the contour plates improves the appearance of the structure and also saves metal in comparison with joints on high-strength bolts. 


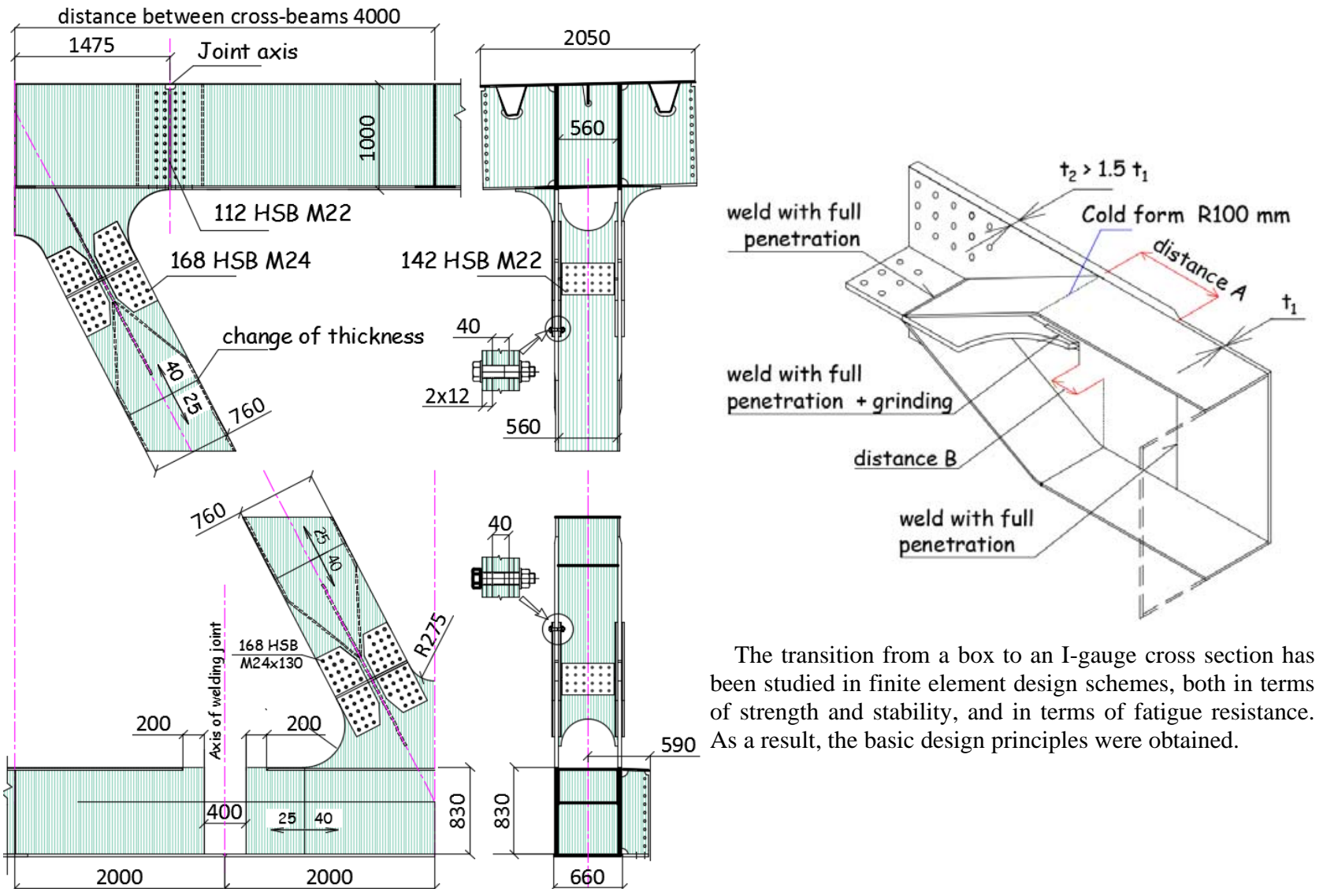

Fig. 15 Truss diagonal elements, and structural solutions.

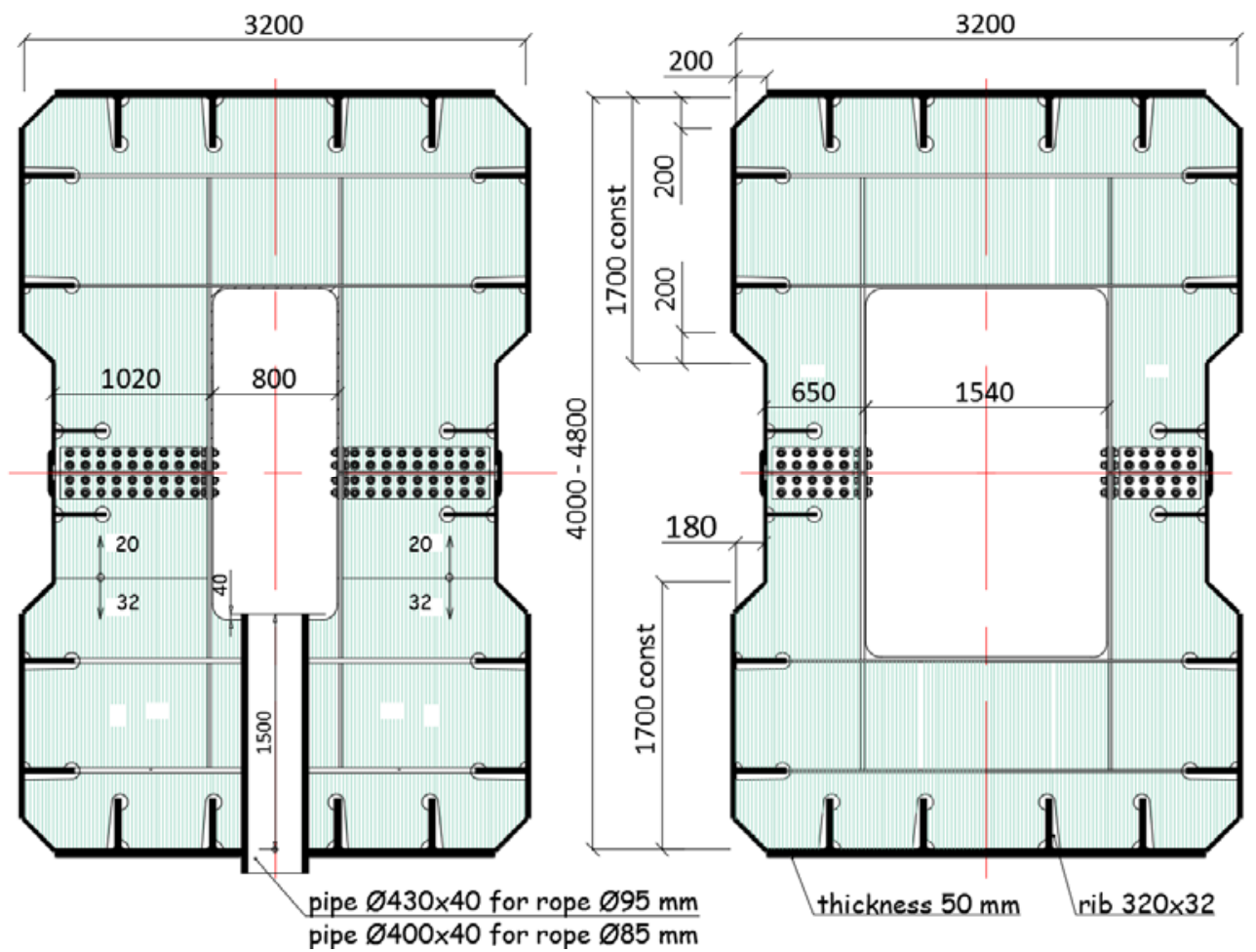

Fig. 16 Arch cross-section at anchorage points and in the regular zone. 


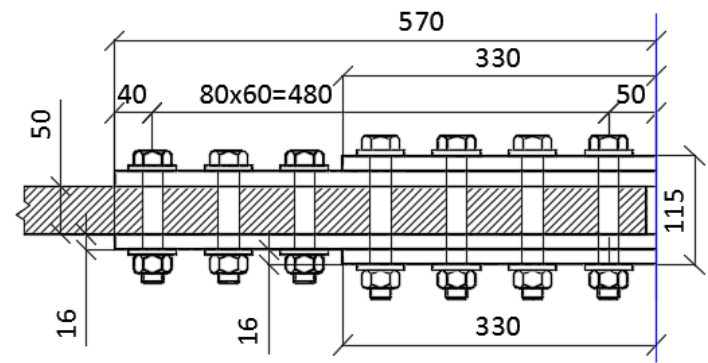

Weight per $1 \mathrm{~m}$ of joint on high strength bolts for sheet $50 \mathrm{~mm}$ per $1 \mathrm{~m}$ of joint:

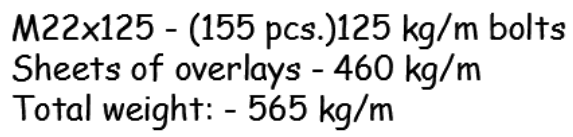

Fig. 17 Comparison of bolted and welded arch joints.

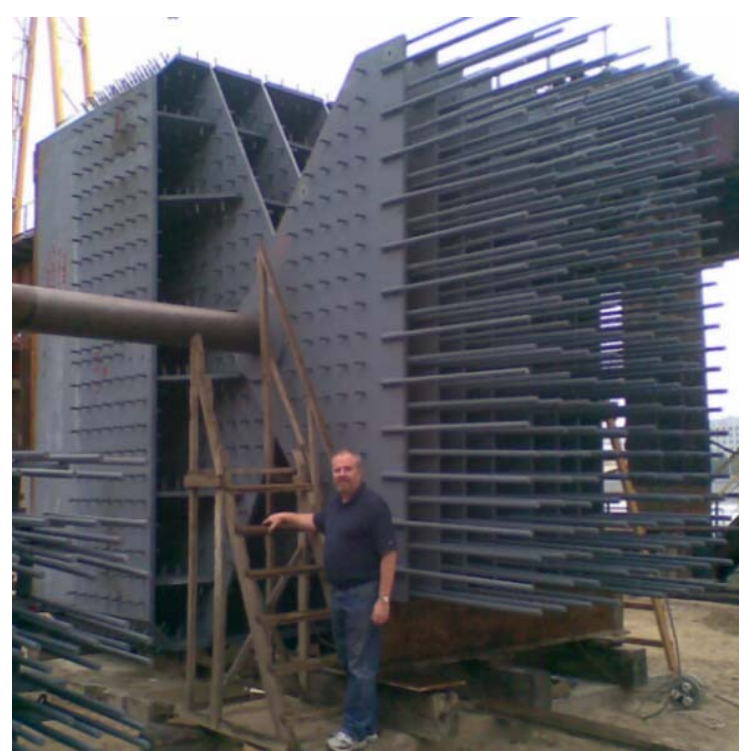

Fig. 18 Temporary arch hinge.

In the arched scheme, the self-weight of the arch with the links is transferred in the scheme with a temporary hinge (Fig. 18), installed between the steel and reinforced concrete parts of the arch. The highest design force transmitted to the hinge is 3,200 t. After the transfer of the arch's own weight, the joint is closed at welding and then concreted, and all other loads are transferred in the scheme without the hinge.

Cable ropes are locked coil with diameters of 83 and $95 \mathrm{~mm}$ with a calculated design force of 300 and 400 tons, respectively (Fig. 19). Wires of ropes are protected against corrosion by a zinc-aluminum coating, cavities between wires are filled with

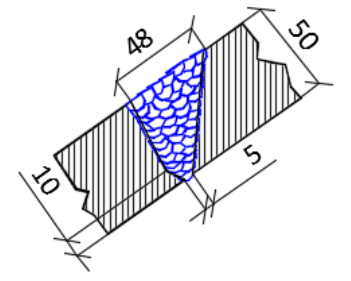

Joint on welding for sheet $50 \mathrm{~mm}$ per $1 \mathrm{~m}$ of joint:

76 passes with wire $\varnothing 1.6 \mathrm{~mm}$.

The weld area is $14.3 \mathrm{~cm}$.

The weld metal weight $11.2 \mathrm{~kg} / \mathrm{m}$

polyurethane. Manufacturer of ropes and sockets is company Bridon-Bekaert.

The lower socket of the rope is forked, which has eyes and a pin. Upper cylindrical socket is with external thread and support washer. The rope length is adjusted by changing the position of the washer on the threaded socket. Possible length changes: extension $280 \mathrm{~mm}$ and shortening $120 \mathrm{~mm}$. A centering anchor of the washer is installed under the support washer, as also a measuring washer, which will allow to estimate the forces from the farm's own weight. The length of the ropes can be regulated.

\section{Arched Bridge Construction}

The bridge was assembled on temporary supports. A truss and arch were installed independently of each other (Fig. 20). The bridge truss was assembled from factory elements, first in plane and then three-dimensional, up to $80 \mathrm{~m}$ long and weighing up to 800 tons. The installation was carried out on a high slipway. The sections were moved from the slipway to the floating support on the water and then delivered to the design position by water. The individual sections were combined in length and width to form a complete structure of a double-deck farm.

The arch is assembled from factory elements (half boxes up to $15 \mathrm{~m}$ long) first into a box and then into sections up to $80 \mathrm{~m}$ long and weighing up to $600 \mathrm{t}$. 


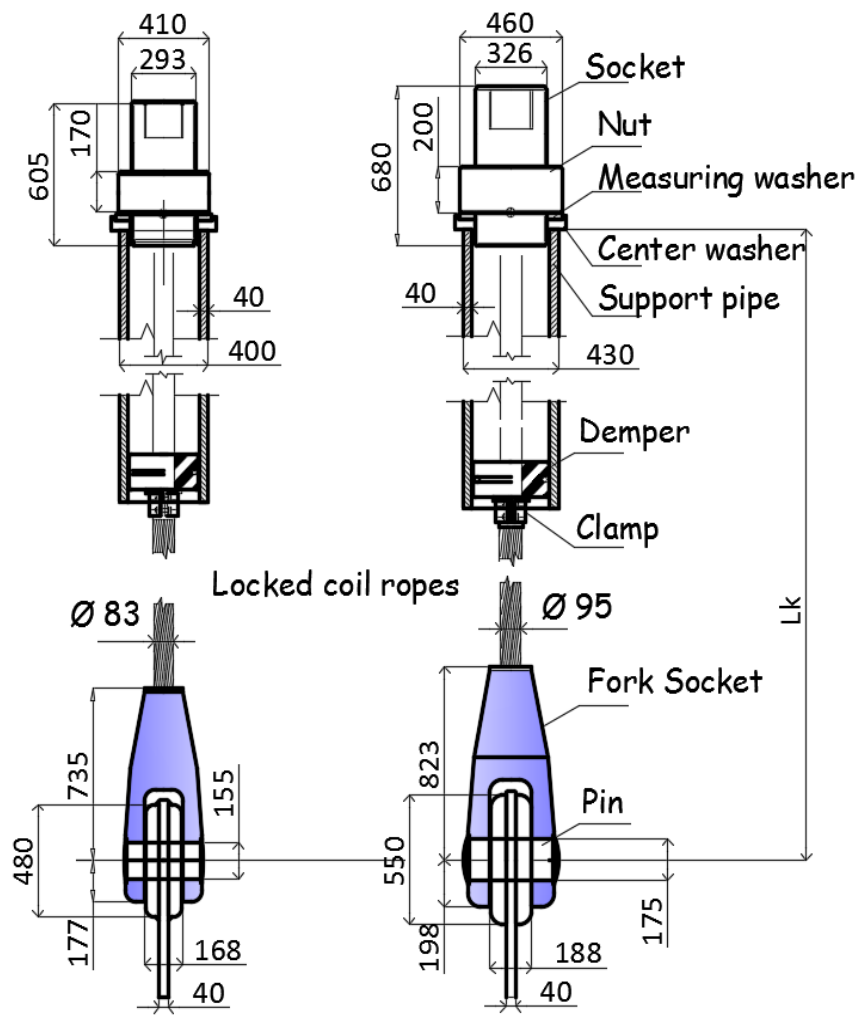

Fig. 19 Rope elements.

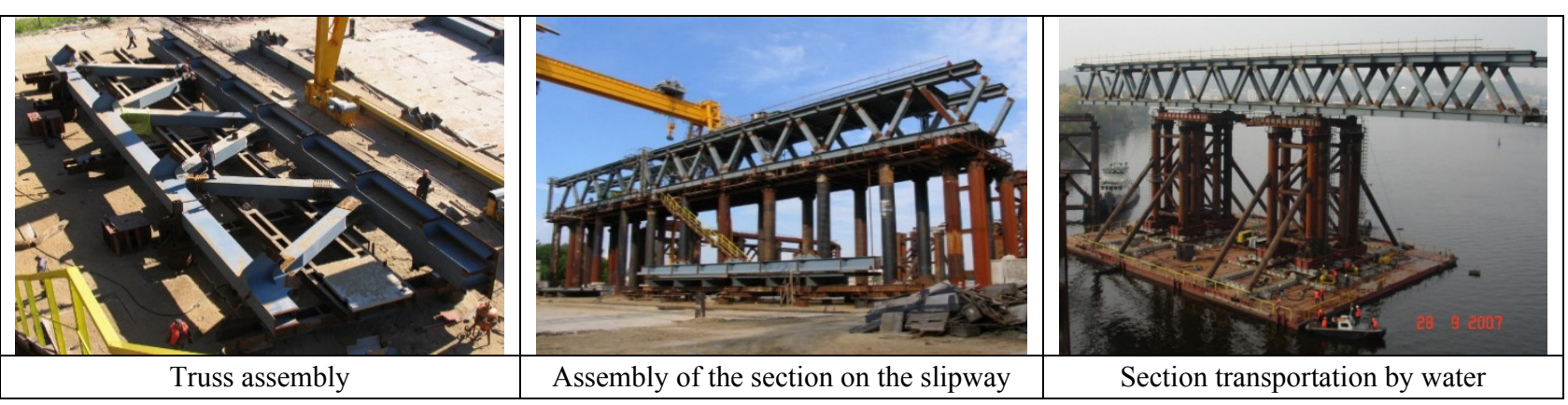

Fig. 20 Assembly fragments of the truss.

The work was carried out on the slipway where the truss was assembled. Further, 80-meter sections were prestressed with a spengel. The sections were removed from the slipway by a floating crane and set in the design position. The central sections of the arch were raised on the ropes by means of jacks (Fig. 21). All but one of the joints of the arch sections were welded together.

Complex spatial topology of links made it necessary to perform preliminary assembly on the ground at special sites. The transverse frame of connections was fixed in the prepared places on arches, and between frames connecting connections which have been preliminarily collected on the ground were mounted.

After all the links between the arches have been installed, the last joint of the arch was closed. To keep the ends of the arch from temperature displacements during welding of the joint, mounting fasteners were provided. In the joint of each arch there were installed 2 fasteners on high-strength bolts, each of which was designed for a force of 2,400 tons. The change of the arch temperature by $10{ }^{\circ} \mathrm{C}$ in one fastener appeared from the normal force up to $600 \mathrm{t}$ and from the moment $900 \mathrm{t}$, totally up to $1,550 \mathrm{t}$. 


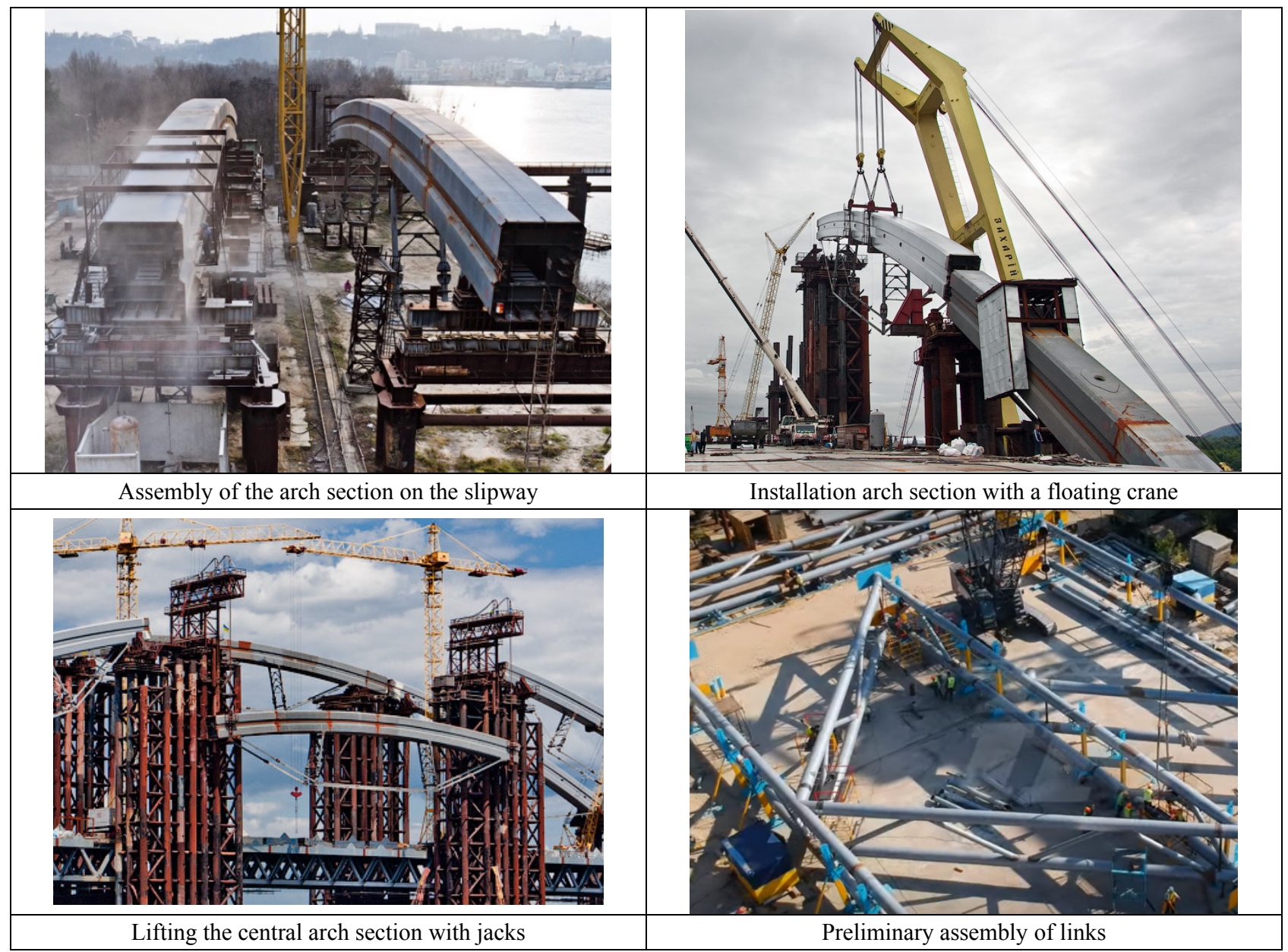

Fig. 21 Assembly fragments of the arch.

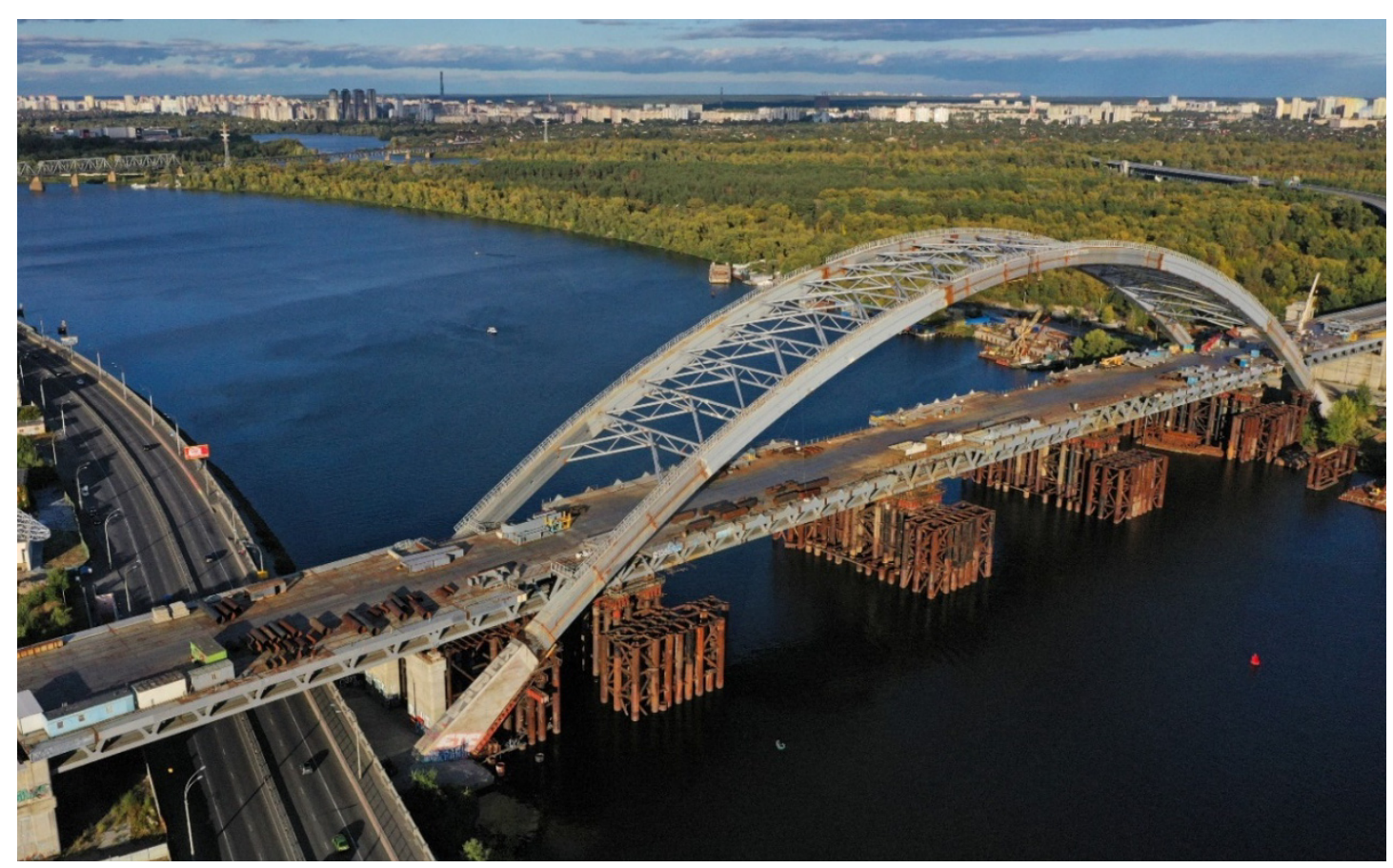

Fig. 22 Today's (2019) bridge view. 
The fasteners were installed on two arches within 6 hours of one night. On the basis of preliminary measurements, it has been defined that from 1 a.m. till 6 a.m. the temperature of the arch practically does not change. That information made it possible to measure the gaps the nights before and to drill holes in the overlay gussets.

6-mm gaps in the holes allowed to install all the bolts (560 pcs.) and preload them with a pneumatic wrench during one night. After fixing the joint it became possible to perform all the necessary works on welding the joint with fixed gaps.

The bottom arch hinges shall be closed at $+10{ }^{\circ} \mathrm{C} \pm$ $5{ }^{\circ} \mathrm{C}$. Fixing elements are provided for closing (as in the case of the central joint). Closure is made by means of reinforcement and concrete (Fig. 22).

The calculated lengths of the hangers (the distance from the eye of the fork anchor to the support washer of the cylindrical anchor) must be specified after measuring the actual position of the anchoring units in the arches. To facilitate the installation of the hangers, the truss lifted above the design level by an average of $1 \mathrm{~m}$. After all the hangers have been wound up, the truss will be lowered and hung from the hangers. After checking the forces in the hangers, the decision will be made to adjust the hangers.

\section{Conclusion}

Podilskyi bridge crossing is very expensive object not only by Ukrainian standards. Its construction began in 2004, when the economy grew by $12-14 \%$. Unfortunately, the situation has changed, so the planned completion date in 2012 has shifted by 10 years. But there is no doubt that the bridge crossing will be completed in the coming years.

\section{References}

[1] Korniiev, M. 2014. Bridge Engineering in Ukraine, Handbook of Bridge Engineering, edited by Wai-Fah Chen, and Lian Duan, 865-905.

[2] Korniiev, M. 2016. "Arch Bridge over Dnipro River in Kyiv.” Presented at 8th International Conference on Arch Bridges, Wroclaw, Poland.

[3] Korniiev, M., Bolikov, V., and Rentmeister, F. E. 2019. "Podilskyi Arche bridge in Kiev." In Proceeding of 9th International Conference on Arch Bridges, 595-603.

[4] Korniiev, M. M., and Fuks, G. B. Patent SU 1158650 A. "Upper Structure of the Railway Bridge Track." 